\title{
Direct imaging of boron segregation to extended defects in silicon
}

\author{
S. Duguay, ${ }^{1, a)}$ T. Philippe, ${ }^{1}$ F. Cristiano, ${ }^{2}$ and D. Blavette ${ }^{1, b)}$ \\ ${ }^{1}$ GPM, Université et INSA de Rouen, UMR CNRS 6634, BP 12, Av. de l'université, 76801 Saint Etienne du \\ Rouvray, France \\ ${ }^{2}$ LAAS-CNRS, University of Toulouse, 7 Avenue du Colonel Roche, 31077 Toulouse, France
}

(Received 5 November 2010; accepted 20 November 2010; published online 13 December 2010)

\begin{abstract}
Silicon was implanted with a high boron dose $\left(5 \times 10^{15}\right.$ at. $\left.\mathrm{cm}^{-2}\right)$ at $30 \mathrm{keV}$ and further annealed at $950{ }^{\circ} \mathrm{C}$ for $30 \mathrm{~s}$. The sample was analyzed using transmission electron microscopy (TEM) and atom probe tomography (APT). TEM images revealed the presence of a high density of dislocation loops $\left(\sim 10^{11} / \mathrm{cm}^{-2}\right)$ distributed around the projected range of implanted atoms. APT reconstructions showed local enrichment of boron in the form of loops that were interpreted as Cottrell atmosphere. Boron enriched rods, interpreted as the $\{113\}$ defects, were also observed. Segregation energies of boron atoms to these defects were estimated to be $\sim 0.35 \mathrm{eV}$. () 2010 American Institute of Physics. [doi:10.1063/1.3526376]
\end{abstract}

The study of the dopant distribution is of crucial importance for recent complementary metal oxide semiconductor (CMOS) transistors. Indeed, the miniaturization of the CMOS devices is accompanied by electrical characteristic dispersion that can have dramatic effects on a technology node. Such dispersion might be the result of dopant redistribution on defects in the semiconductor. As far as p-type doping in silicon is concerned, boron has been extensively studied by the semiconductor industry for the past decades. Usually introduced in Si by ion implantation to create controlled dopant profiles, boron can however interact with the defects generated during the implantation step. It is indeed known for years that boron mainly diffuses by an interstitial mechanism. ${ }^{1,2}$ The boron diffusivity in $\mathrm{Si}$ is then directly related to the concentration of self-interstitial in the semiconductor lattice. ${ }^{2,3}$ Above a given concentration and after annealing $\left(700-1000{ }^{\circ} \mathrm{C}\right)$, a few percent of the self-interstitials generated by implantation are known to form structural defects. The latter mainly consist of rod-like $\{113\}$ defects and Frank dislocation loops (faulted or perfect). Those extended defects are then located either around the projected ion range ( $\mathrm{Rp})$ in $\mathrm{Si}$ or at the amorphous/crystalline postimplantation interface [end-of-range (EOR) defects]. ${ }^{4}$ The interstitials dissolved from those defects were widely studied in terms of boron transient enhanced diffusion, which is a major problem to control the electrical junction depth. ${ }^{5-7}$ More recently, dislocation engineering was also particularly studied in order to suppress the thermal quenching in indirect band-gap semiconductors with the objective to produce Si-based electroluminescent diodes structures. 8

Whereas the trapping of boron on those extended defects was already demonstrated by the presence of a typical immobilization peak on secondary ion mass spectrometry (SIMS) profiles, ${ }^{10,11}$ no direct proof of this phenomenon was brought. By coupling SIMS and transmission electron microscopy (TEM), some authors evidenced the different trapping efficiency of $\{113\}$ defects and dislocation loops ${ }^{11}$ others even extracted a segregation energy of boron $(0.74 \mathrm{eV})$ on those extended defects. ${ }^{12}$

\footnotetext{
${ }^{a)}$ Electronic mail: sebastien.duguay @univ-rouen.fr.

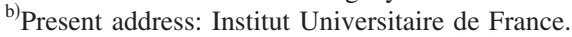

However, atom probe tomography (APT) recently proved its capacity to analyze poorly conductive materials such as semiconductors ${ }^{13}$ at the almost atomic scale in $\mathrm{Si}^{14}$ As an example, APT showed that n-type dopants such as As and $\mathrm{P}$ decorated end-of-range defects in implanted $\mathrm{Si}$ (Ref. 13) or polycrystalline $\mathrm{Si}^{15}$ The distribution of implanted boron was also recently studied using APT. At concentration above its solubility limits and after annealing, nano-B-Si clusters were observed and often associated to the wellknown boron interstitial clusters. ${ }^{16,17}$ The latter were then assimilated to metastable precipitates of B in Si and clearly linked to be responsible for the electrical deactivation of $\mathrm{B}$ in $\mathrm{Si}^{17,18}$ However, no segregation was evidenced, even if those precipitates were observed in the presence of large amount of $\{311\}$ defects, suggesting a competition between the precipitation and segregation-to-defect phenomena. However, no direct evidence of boron segregation to extended defects was brought by APT.

Two methods can be used to induce and study the decoration of extended defects. The first one consists of creating those defects by implanting a substrate containing the impurity to study until its amorphization and annealing it to create decorated EOR defects. The second solution is to induce the extended defects by self-ion implantation of the impurity (here B) in Si. The advantage of such a solution enables the creation of a large density of defects in a one-step process as already demonstrated in the case of Si-based electroluminescent diodes structures. ${ }^{9}$ In the latter work, the population of extended defects formed around $\mathrm{Rp}$ is studied as a function of the implantation energy of boron, the dose being 1 $\times 10^{15}$ at. $\mathrm{cm}^{-2}$ and the annealing conditions at $950{ }^{\circ} \mathrm{C}, 20$ min under $\mathrm{N}_{2}$. As an example, a $4 \times 10^{9}$ at. $\mathrm{cm}^{-2}$ areal density of dislocation loops is obtained for $30 \mathrm{keV}$ implants. A higher areal density of defects is compulsory to facilitate APT analysis. Indeed, taking into account the fact that APT has a relatively low field-of-view (FOV) (usually to 50 $\times 50 \mathrm{~nm}^{2}$ ), the observation of a segregation to defects (if existing) will be statistically certain with a minimum of 5 $\times 10^{10} \mathrm{~cm}^{-2}$ areal density of defects.

As compared to this work and in order to get a larger amount of defects, the ${ }^{11} \mathrm{~B}$ implantation dose in a [100]oriented silicon wafer was increased to $5 \times 10^{15}$ at. $\mathrm{cm}^{-2}$ 

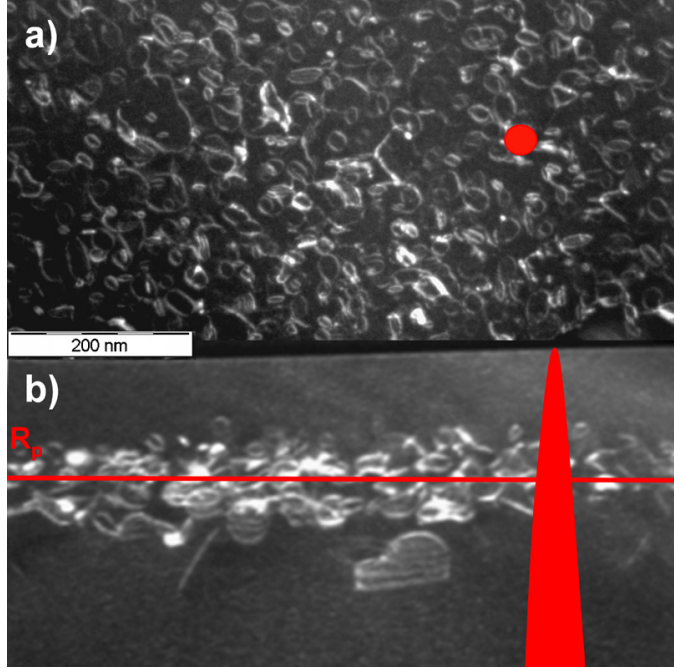

FIG. 1. (Color online) TEM images of a Si sample implanted with ${ }^{11} \mathrm{~B}$ atoms at $5 \times 10^{15}$ at. $\mathrm{cm}^{-2}$ with an energy of $30 \mathrm{keV}$ and annealed at $950{ }^{\circ} \mathrm{C}$ for $30 \mathrm{~s}$ under $\mathrm{N}_{2}$ : (a) plane-view image, (b) cross section image. The area and cross section of APT samples are superimposed to the images in order to evidence that at least one loop should be observed in the volume analyzed by APT

with an energy of $30 \mathrm{keV}$, leading to a Rp of $\sim 120 \mathrm{~nm}$ and a maximum $\mathrm{B}$ concentration value of $4 \times 10^{20}$ at. $\mathrm{cm}^{-3}$ (or $0.8 \%$ ). In the meantime, the annealing duration was decreased to $30 \mathrm{~s}$ keeping the annealing temperature to $950{ }^{\circ} \mathrm{C}$.

The sample was then specifically prepared using focus ion beam milling in order to prepare a sharp nanometric tip $(\mathrm{R} \sim 50 \mathrm{~nm})$ for APT characterization. ${ }^{16}$ TEM and SIMS analyses were also carried out on the sample. The latter (not shown here) did not demonstrate a boron immobilization, usually linked to boron trapping on defects. However, TEM analyses [Figs. 1(a) and 1(b)] clearly revealed the presence of a high density of defects. Figure 1(a) presents a TEM plane-view image of those defects. The latter appears mainly as dislocation loops. A rough estimation of the density and diameter of those defects leads, respectively, to $\sim 1$ $\times 10^{11}$ at. $\mathrm{cm}^{-2}$ and $\sim 30 \mathrm{~nm}$, which are adequate for APT analyses. A typical FOV of an APT analysis is plotted in the figure showing that at least one defect should be observed in an APT experiment. Figure 1(b) presents the TEM cross section analysis of the implanted sample. Dislocation loops appear as distributed around $\mathrm{Rp}$, indicating that they were induced by the $\mathrm{B}$ implantation as a result of a nonamorphizing implant. The majority of the defects are observed as dislocation loops. No rod-like defects were clearly deduced from TEM observations.

Next, APT characterizations were performed using a CAMECA LAWATAP instrument. An amplified ytterbiumdoped laser operating at a wavelength of $343 \mathrm{~nm}$, with $350 \mathrm{fs}$ pulse duration and a $100 \mathrm{kHz}$ repetition rate, was used. During the analysis, the tip was cooled at a temperature of $80 \mathrm{~K}$ and the energy per pulse was chosen in order to obtain a constant $\mathrm{Si}^{2+} / \mathrm{Si}^{+}$count ratio for analysis reproducibility. A typical mass spectrum of boron implants in Si can be found, e.g., in Ref. 16.

Figure 2 shows the three dimensional distribution of boron atoms (one dot represents one atom) after APT analysis and reconstruction. The distribution of $\mathrm{B}$ atoms presents clear inhomogeneities located around the $\mathrm{Rp}$ of implanted

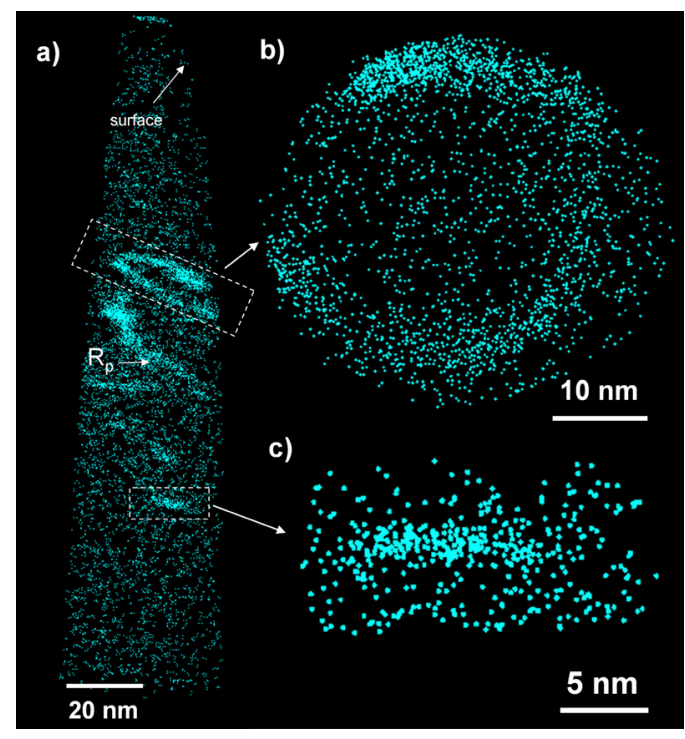

FIG. 2. (Color online) APT reconstructions of a Si sample implanted with ${ }^{11} \mathrm{~B}$ atoms at $5 \times 10^{15}$ at. $\mathrm{cm}^{-2}$ with an energy of $30 \mathrm{keV}$ and annealed at $950{ }^{\circ} \mathrm{C}$ for $30 \mathrm{~s}$ under $\mathrm{N}_{2}$ : (a) reconstruction of the entire analysis showing the decoration of extended defects by boron. The decoration of two types of extended defects was observed: (b) dislocation loop, (c) rod-like defects.

boron atoms [Fig. 2(a)]. By looking closely to the latter, it can be evidenced that boron inhomogeneities have the shape of loops or parts of loops passing through the volume of analysis. A loop of diameter $\sim 34 \mathrm{~nm}$, almost fully embedded in the volume of analysis, is presented in Fig. 2(b). An inhomogeneity, fully embedded in the analyzed volume, was also observed as a rod [Fig. 2(c), $15 \mathrm{~nm}$ length, $4 \mathrm{~nm}$ thick]. Note that several APT experiments confirmed these observations.

The implantation conditions led to a maximum B concentration value $\left(\sim 4 \times 10^{20}\right.$ at. $\mathrm{cm}^{-3}$ or $\left.0.8 \%\right)$ far above the solubility limit of B at $950{ }^{\circ} \mathrm{C}\left(\sim 10^{20} \mathrm{~cm}^{-3}\right)$. Hence, precipitation is expected as already shown by APT. ${ }^{17}$ However, in our case, the shape of the observed inhomogeneities by coupling of TEM and APT analyses clearly demonstrates that boron segregation to implantation-induced extended defects is predominant upon precipitation Moreover, boron appears as distributed as a cloud around the observed defects [Figs. 2(b) and 2(c)], indicative of the formation of Cottrell atmospheres. ${ }^{19,20}$ The diffusion of boron atoms as well as the segregation are driven by the strain field (responsible for the luminescence properties of such kind of samples ${ }^{8}$ ) around dislocation lines. Relaxation of this field by boron segregation is energetically favorable for both the dislocation and interstitial atoms. Assuming the equilibrium segregation, a segregation energy $(\Delta \mathrm{E})$ can then be derived from the averaged concentration of $B$ in the Cottrell atmosphere $\left(C_{B}\right)$ and that in the matrix around the defect $\left(\mathrm{C}_{\mathrm{A}}\right)$ as $\mathrm{C}_{\mathrm{B}} / \mathrm{C}_{\mathrm{A}}$ $=\exp (\Delta \mathrm{E} / \mathrm{kT}) \cdot \mathrm{C}_{\mathrm{A}}$ and $\mathrm{C}_{\mathrm{B}}$ were derived from APT data using a statistical method based on the distribution of distances between the first nearest neighbors (the so-called 1NN method) between $\mathrm{B}$ atoms in a selected region containing the decorated defects. ${ }^{21}$ The segregation energy for both types of defects was found close to each other $\left(0.35^{+} / 0.01 \mathrm{eV}\right.$ energy for loop and $0.38^{+} / 0.06 \mathrm{eV}$ for rod-like defect). These values are clearly lower than the ones extracted on the segregation of dislocation loops by Xia et al., ${ }^{12}$ i.e., $0.74 \mathrm{eV}$ 
using SIMS and TEM analyses. The authors considered that the core radius of the toroidal regions was equal to the average interatomic spacing in silicon that is clearly not true as demonstrated here experimentally. It must also be pointed out that the $C_{B} / C_{A}$ ratio (and hence the segregation energy) keeps constant with the matrix concentration $\left(C_{B}\right)$, which clearly depends on the depth due to the implantation process. Consequently, the $\Delta \mathrm{E}$ was found constant whatever the depth where the defects were observed. A kinetic study (not presented here) was also carried out at $950{ }^{\circ} \mathrm{C}$. After $10 \mathrm{~min}$ annealing, boron was also found to segregate as Cottrell atmospheres on dislocation loops. Their diameters were observed larger than for the $30 \mathrm{~s}$ annealing by TEM and APT. However, the segregation energy was found constant as compared to the $30 \mathrm{~s}$ annealing, i.e., a constant $\mathrm{C}_{\mathrm{B}} / \mathrm{C}_{\mathrm{A}}$ ratio. This is an indication that the thermal equilibrium might already be reached after a $30 \mathrm{~s}$ annealing, justifying our calculations. However, no segregation on rod-like defects was observed after a 10 min annealing, suggesting that they all dissolved for this thermal budget.

In conclusion, the direct imaging of boron trapping on extended defects in silicon was clearly demonstrated, thanks to the combined use of APT and TEM. APT reconstructions showed local enrichment of boron in the form of loops that were interpreted as Cottrell atmosphere. Boron enriched rods, interpreted as the so-called $\{113\}$ defects, were also observed. Segregation energies of boron atoms to these defects were estimated to be $\sim 0.35 \mathrm{eV}$.

The authors thank the CEMES laboratory (Toulouse, France) for the use of their TEM facilities and the French National Agency for financial support (Project No. ANATEME ANR-08-JCJC-0129-01).
${ }^{1}$ A. E. Michel, W. Rausch, P. A. Ronsheim, and R. H. Kastl, Appl. Phys. Lett. 50, 416 (1987).

${ }^{2}$ D. J. Eaglesham, P. A. Stolk, H.-J. Gossmann, and J. M. Poate, Appl. Phys. Lett. 65, 2305 (1994).

${ }^{3}$ F. Marou, A. Claverie, Ph. Salles, and A. Martinez, Nucl. Instrum. Methods Phys. Res. B 55, 655 (1991).

${ }^{4}$ C. Bonafos, D. Mathiot, and A. Claverie, J. Appl. Phys. 83, 3008 (1998).

${ }^{5}$ C. Bonafos, A. Claverie, D. Alquier, C. Bergaud, A. Martinez, L. Laânab, and D. Mathiot, Appl. Phys. Lett. 71, 365 (1997).

${ }^{6}$ A. Claverie, L. F. Giles, M. Omri, B. de Mauduit, G. Ben Assayag, and D. Mathiot, Nucl. Instrum. Methods Phys. Res. B 147, 1 (1999).

${ }^{7}$ C. Bonafos, M. Omri, B. de Mauduit, G. Ben Assayag, A. Claverie, D. Alquier, A. Martinez, and D. Mathiot, J. Appl. Phys. 82, 2855 (1997).

${ }^{8}$ W. L. Ng, M. A. Lourenço, R. M. Gwilliam, S. Ledain, G. Shao, and K. P. Homewood, Nature (London) 410, 192 (2001).

${ }^{9}$ M. Milosavljević, G. Shao, M. A. Lourenco, R. M. Gwilliam, and K. P. Homewood, J. Appl. Phys. 97, 073512 (2005).

${ }^{10}$ C. Bonafos, A. Martinez, M. M. Faye, C. Bergaud, D. Mathiot, and A. Claverie, Nucl. Instrum. Methods Phys. Res. B 106, 222 (1995).

${ }^{11}$ E. M. Bazizi, P. F. Fazzini, C. Zechner, A. Tsibizov, H. Kheyrandish, A. Pakfar, L. Ciampolini, C. Tavernier, and F. Cristiano, Mater. Sci. Eng., B 154-155, 275 (2008).

${ }^{12}$ J. Xia, T. Saito, R. Kim, T. Aoki, Y. Kamakura, and K. Taniguchi, J. Appl. Phys. 85, 7597 (1999).

${ }^{13}$ K. Thompson, P. L. Flaitz, P. Ronsheim, D. J. Larson, and T. F. Kelly, Science 317, 1370 (2007).

${ }^{14}$ E. Cadel, F. Vurpillot, R. Larde, S. Duguay, and B. Deconihout, J. Appl. Phys. 106, 044908 (2009).

${ }^{15}$ S. Duguay, A. Colin, D. Mathiot, P. Morin, and D. Blavette, J. Appl. Phys. 108, 034911 (2010).

${ }^{16}$ M. Ngamo, S. Duguay, F. Cristiano, K. Daoud-Ketata, and P. Pareige, J. Appl. Phys. 105, 104904 (2009).

${ }^{17}$ O. Cojocaru-Mirédin, D. Mangelinck, and D. Blavette, J. Appl. Phys. 106, 113525 (2009).

${ }^{18}$ M. Ngamo, Ph.D. thesis, University of Rouen, 2010

${ }^{19}$ H. Cottrell and B. A. Bilby, Proc. Phys. Soc., London, Sect. A 62, 49 (1949).

${ }^{20}$ D. Blavette, E. Cadel, A. Fraczkiewicz, and A. Menand, Science 286, 2317 (1999).

${ }^{21}$ T. Philippe, F. De Geuser, S. Duguay, W. Lefebvre, O. Cojocaru-Mirédin, G. Da Costa, and D. Blavette, Ultramicroscopy 109, 1304 (2009). 